\section{Ludwig's angina - an emergency complication arising from delayed dental treatment: The experience in a Nigerian tertiary institution}

\author{
Thomas Owobu, ${ }^{1}$ Edugie Ekuase, ${ }^{2}$ Oba O. Azah, ${ }^{1}$ Sulaiman S. Adamu, ${ }^{1}$ \\ Babatunde O. Bamgbose ${ }^{3 *}$
}

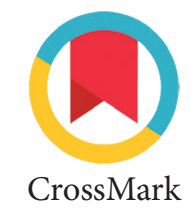

CrossMark

\title{
Abstract
}

Objective: The aim of this paper was to report two cases and management of Ludwig's angina in a Nigerian tertiary health facility.

Methods: Ludwig's angina is an acute onset, potentially lifethreatening surgical emergency in young adults that presents with rapidly expanding, diffuse inflammation of the submandibular and sublingual spaces, mostly from odontogenic infections.
Results: One of the sequelae is airway compromise. Given the sparse health facilities and poor access to health, we observed an increasing rate of Ludwig's angina secondary to odontogenic infections in our practice. We present two cases of Ludwig's Angina arising from delayed dental treatment.

Conclusion: Socioeconomic status and unrest due to insurgency have hampered early presentation and management
'Dental and Maxillofacial Department, Federal Medical Center, Nguru, Yobe State

${ }^{2}$ Department of Chemistry and Forensic Sciences, Savannah State University, Georgia

${ }^{3}$ Oral Diagnostic Sciences Department, Faculty of Dentistry, Bayero University Kano, Kano
*Correspondence to: Babatunde 0. Bamgbose, Oral Diagnostic Sciences Department, Faculty of Dentistry, Bayero University Kano, Kano drtundebamgbose@yahoo.com

Received: 8 May 2020

Revised: 2 July 2018

Accepted: 27 July 2019

Available Online: 1 August 2020

Keywords: Ludwig's angina, Management, Surgical emergency

Cite this Article: Owobu T, Ekuase E, Azah 00, Adamu SS, Bamgbose B0. 2020. Ludwig's angina - an emergency complication arising from delayed dental treatment: The experience in a Nigerian tertiary institution. Journal of Dentomaxillofacial Science 5(2): 129-133. D0l: 10.15562/ jdmfs.v5i2.1082

\section{Introduction}

Ludwig's angina has been described as a surgical emergency that is potentially life-threatening, with rapidly expanding, diffuse inflammation of the submandibular and sublingual spaces that occurs most often in young adults with dental infections. ${ }^{1-2}$ It is a severe form of diffuse cellulitis of acute onset. The disorder can also occur in children and may result in severe airway compromise..$^{2-5}$

Ludwig's angina was initially described in 1836 by German physician Wilhelm Frederick von Ludwig. ${ }^{6-8}$ His description was based on the observation of five patients with "gangrenous induration of the connective tissues of the neck that advanced to involve the tissues that cover the small muscles between the larynx and the floor of the mouth., There are many alternative names of Ludwig's Angina, including cynanche, carbuculusgangraenosus, angina maligna, morbusstrangularis, and garotillo. Although traditionally associated with pain of cardiac origin, the term "angina" is derived from the Latin word for choke (angere) and the Greek word for strangle (ankhone). ${ }^{5}$ In the case of Ludwig's angina, it refers to the feeling of strangling and choking secondary to lingual airway obstruction, which is the most serious potential complication of this condition. ${ }^{5}$ Deep neck infections may be a rare but potentially fatal complication of pulpal abscess especially the last lower molars. ${ }^{6-12}$
Before the development of penicillin by Alexander Fleming and its mass production in the 1950s, mortality associated with Ludwig's angina exceeded $50 \% .^{7}$ As a result of current antibiotic therapies and surgical techniques, current mortality estimates are in the range of $8 \%{ }^{8}$

The aim of this paper was to report two cases and management of Ludwig's angina in a Nigerian tertiary health facility.

\section{Case Report}

A 20-year-old Fulani girl initially presented at a primary health facility complaining of toothache associated with right mandibular swelling before visiting the oral surgery clinic with a chief complaint of inability to open mouth, pain, fever, dysphagia, and bilateral jaw swelling of five days duration. On examination, she was toxic in appearance, profusely sweating, and in obvious respiratory distress figure 1 . Her temperature was $38.9^{\circ} \mathrm{C}$ with a pulse rate of 96 beats per minutes, blood pressure of $130 / 80 \mathrm{mmHg}$, and a respiratory rate of 26 breaths per minute. Mouth opening was limited to $1.3 \mathrm{~cm}$ (interincisal distance) with an impacted and carious right mandibular third molar. Extra-oral swelling was indurated, non-fluctuant, involving bilateral submandibular and sublingual spaces with mediastinal extension. A spot diagnosis of Ludwig's 


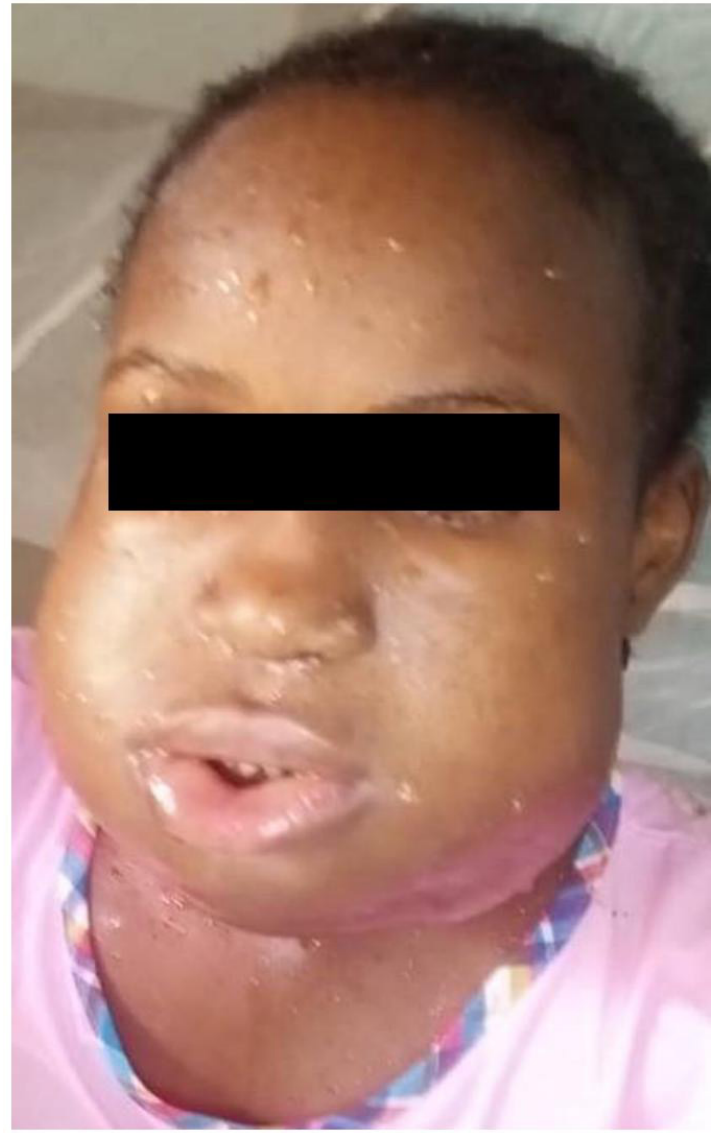

Figure 1 Ill-looking 20-year-old female with poor mouth opening and bilateral swelling of submandibular, submental and mediastinal spaces

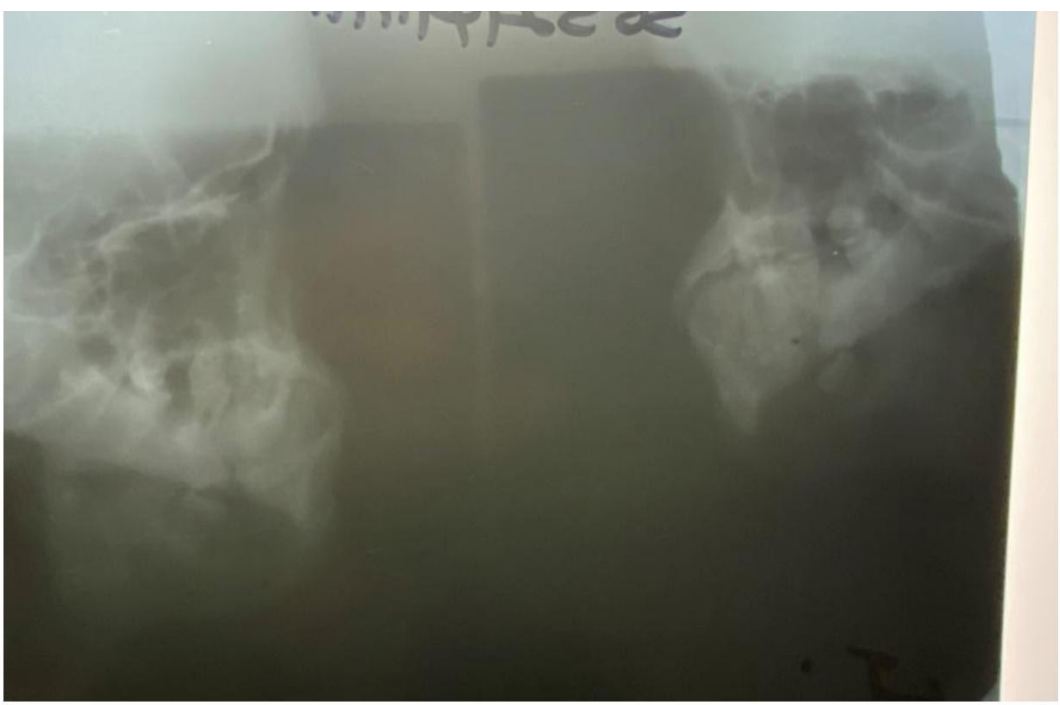

Figure 2 Left and right oblique lateral jaws demonstrating impacted mandibular third molars

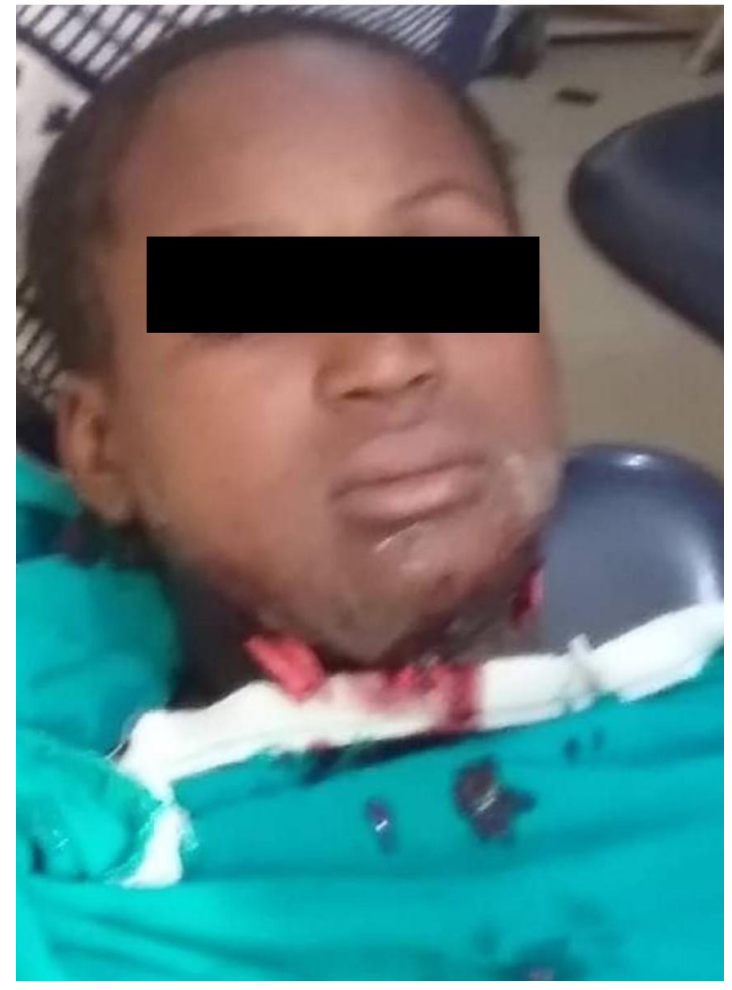

Figure 3 24-hour post-operative review of the active surgical drains

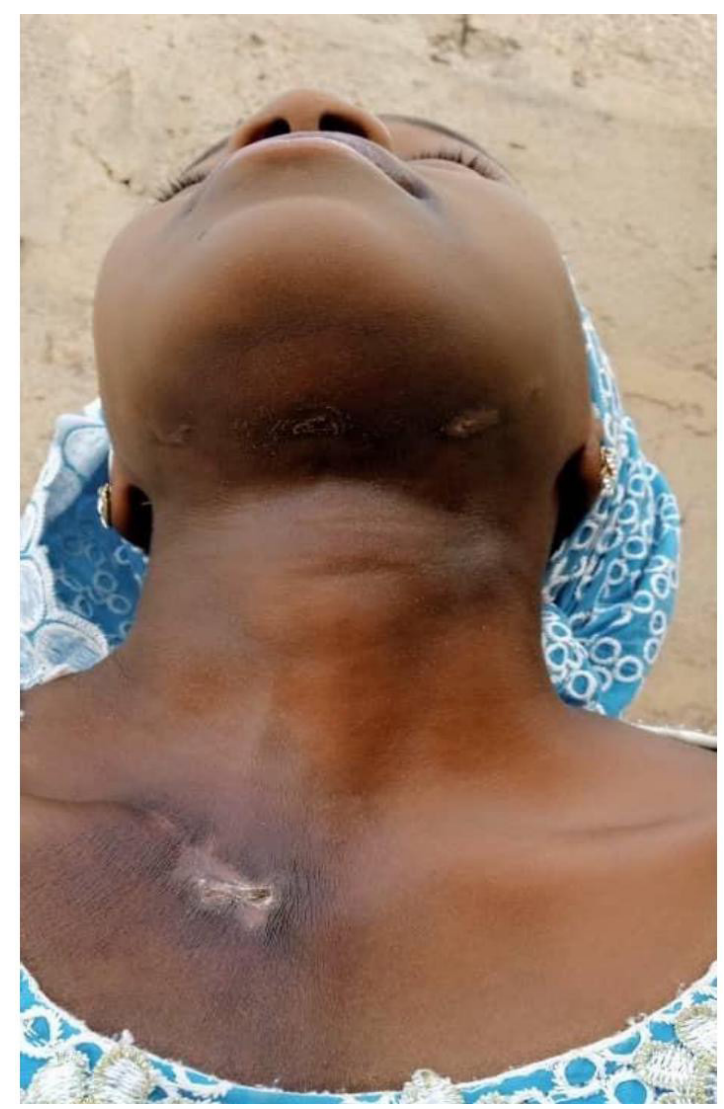

Figure 4 Residual scar following healing of incision sites 


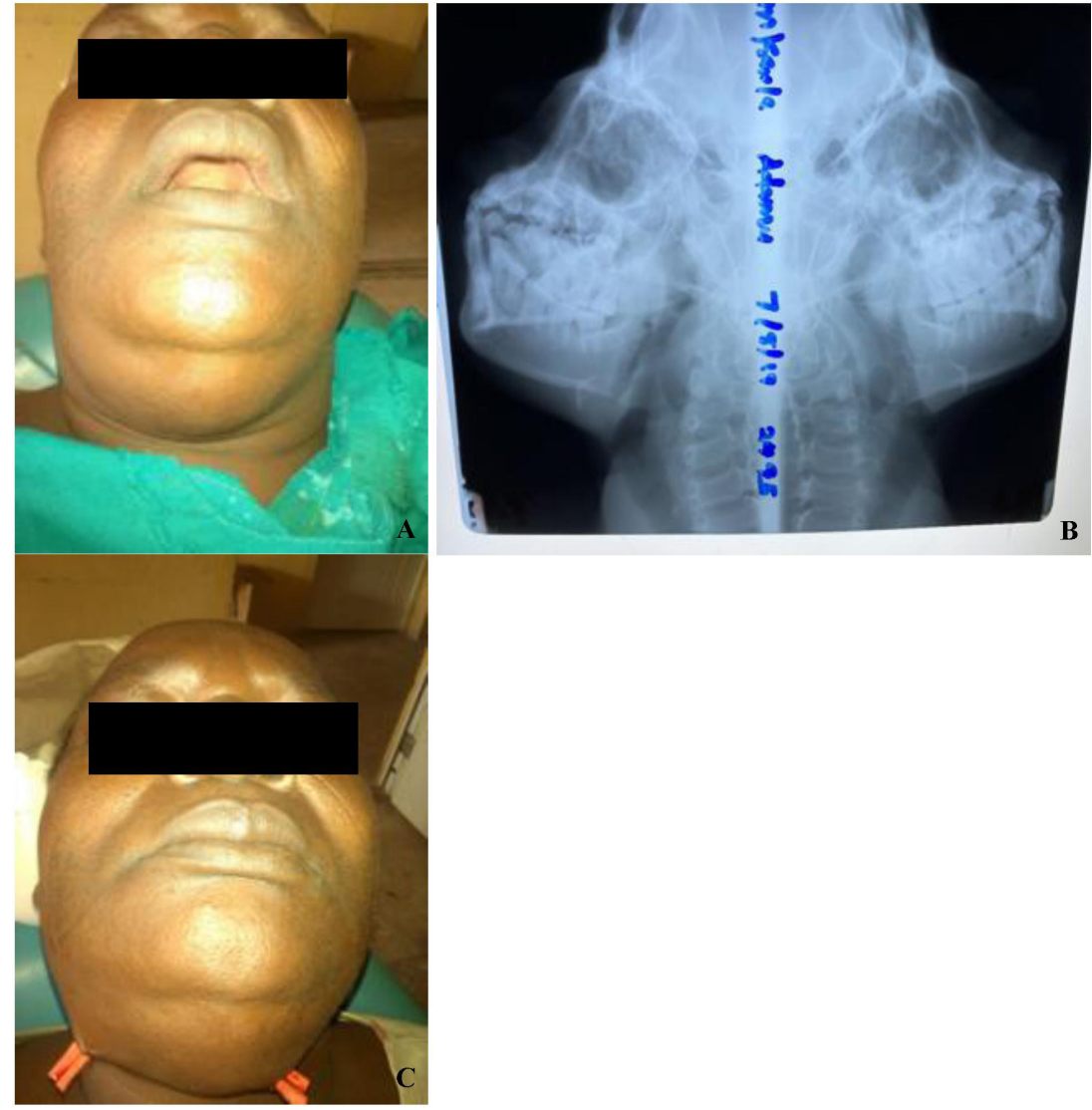

Figure 5 A. 46-year-old female with swelling of the right submandibular space spreading to the left submandibular space with associated swelling of floor of the mouth, B. Left and right oblique lateral jaws showing submandibular swelling on the right with no obvious associated carious or impacted tooth, C. Bilateral submandibular corrugated drains in situ

Angina was made based on clinical presentation. Left and right oblique laterals revealed the impacted mandibular third molar figure 2. Patient was admitted for surgical decompression under general anesthesia. Stab incisions were made in the submandibular spaces bilaterally, connecting the sublingual space and mediastinal spaces. A sinus forceps was introduced to open up the tissue spaces and pus was drained. The wound was irrigated with $(0.9 \% \mathrm{w} / \mathrm{v})$ normal saline solution, and corrugated rubber drains were placed in the incisions and secured to the skin with 3/0 silk sutures figure 3. Microbial culture and sensitivity (MCS) result from the pus collected revealed a polymicrobial bacterial infection that includes Streptococcus species, Staphylococcus, Fuso- bacterium, and Bacteroides species. Patient was place on intravenous cefuroxime $750 \mathrm{mg} 8$ hourly, metronidazole $500 \mathrm{mg} 8$ hourly, gentamycin $80 \mathrm{mg} 12$ hourly and diclofenac $75 \mathrm{mg} 8$ hourly. The impacted mandibular third molar tooth was removed after three days when mouth opening had improved. The drains were left in place until they were no longer active. Patient recovery was satisfactory figure $4 \mathrm{~A}$, figure 4B. She was discharged home on the sixth day with oral antibiotics and analgesics.

A 46-year-old pregnant known diabetic patient presented at the Emergency Room of the hospital with a three-week history of worsening toothache. Prior to presentation, she visited a local pharmacy for over-the-counter medications. By the third week, she was brought to our facilities. On examination, she appeared unwell, with an irregularly irregular pulse of $128 \mathrm{bpm}$ and febrile of $39.3^{\circ} \mathrm{C}$, drooling saliva and in obvious respiratory distress. Mouth opening was limited. There was a brawny tender swelling over the right submandibular region, flour of the mouth was raised with elevated tongue posture and dysphagia figure $5 \mathrm{~A}$. The patient was in acute respiratory distress associated with cyanosis. Blood pressure was $140 / 80 \mathrm{mmHg}$, random blood glucose level was within normal range with a PCV of $26 \%$. ESR was $56 \mathrm{~mm} / \mathrm{h}$ with markedly high white cell count of $\left(51 \times 10^{9}\right)$. Based on these parameters and presentations, Ludwig's Angina was suspected. She was immediately commenced on intravenous antibiotics and analgesic. No carious tooth was visible on the X-Rays except for periodontal pockets of the right second mandibular molar with furcation involvement figure 5B. By the second day, her symptoms improved with daily maintaining a normal breathing rate and pattern with no oxygen desaturations below $97 \%$ on room air with pulse oximetry. Patient was transferred to specialty ward for surgical decompression under general anesthesia. Separate stab incision was made in relation to the submandibular spaces bilaterally and sublingual spaces. A sinus forceps was introduced to open up the tissue spaces and pus was drained. The wound was irrigated with $(0.9 \% \mathrm{w} / \mathrm{v})$ normal saline solution, and a separate corrugated rubber drain was placed and secured to the skin with $3 / 0$ silk sutures figure $5 \mathrm{C}$. By the 4th day following her admission, her symptoms had fully resolved, and she was discharged from hospital on oral antibiotics, multivitamins and analgesics.

Ethical approval was obtained from the research ethical review committee of Federal Medical Center, Nguru, before the commencement of the study. The procedures in the study were in accordance with the ethical standards of responsible conduct of research and the Helsinki Declaration of 1975, as revised in 2008.

\section{Discussion}

Although Ludwig's Angina cases have been described as a surgical emergency that is potentially life-threatening but were observed rarely in 
everyday general dental practice..$^{1-2,4-5}$ Recently, there has been an upsurge on the incidence of Ludwig's Angina presented at Accident and Emergency Unit and Dental Outpatient Clinic of the Federal Medical Centre, Nguru, Yobe State, Nigeria. Most cases presented were usually of odontogenic origin with carious second or third mandibular molars implicated. Only a few were from other sources. Various reasons have been attributed to this phenomenon. These include patient's socioeconomic status, insurgency in this part of the country, cultural belief and ignorance. Prior to presentation, patient usually have a history of mild toothache which later become severe. Unfortunately, some patients result to self-medication either because they could not afford to pay for extraction of an abscessed tooth/ teeth that may require surgical dissimpaction, or because of inability to access the available tertiary health institutions in the region on account of insurgency. Although the reason for the upsurge in cases is still unclear, available patients' records revealed that most of the patients have previously accessed our health facility on account of toothache and treatments were deferred because patients could not afford the prescribed care. Some other patients could not access health care due to the ongoing insurgency attack in the region of the country. Almost all the cases of Ludwig's Angina previously recorded at this hospital and those still on treatment, are odontogenic in origin. Only a few were from other sources.

In Nigeria, $80 \%$ of cases of Ludwig's Angina are secondary to odontogenic infections. ${ }^{8}$ The Mandibular third molar is the most common site of origin in this environment. However, the second mandibular molar is also often involved. ${ }^{2,12}$

The submandibular space is subdivided by the mylohyoid muscle into the sublingual space superiorly and submaxillary space inferiorly. Once an infection is present, it may spread freely through tissue planes because of communicating spaces. ${ }^{9}$ This open communication between spaces results in the bilateral nature of Ludwig's angina. Infection can also spread to pharyngomaxillary and retropharyngeal spaces. ${ }^{3,9}$

Odontogenic infections are the most common route for the introduction of bacteria into the submandibular space, however, other causes exist. Mandible fractures, piercings of the lingual frenulum and tongue, and injection of the jugular vein all provide routes of access. ${ }^{1,4,7}$ Neoplasms and salivary calculi may also alter the normal anatomy and result in persistent infections leading to Ludwig's angina.

Ludwig's angina is caused by a polymicro-bial bacterial infection that includes group a streptococcus species. ${ }^{3,8}$ Other commonly cultured organisms include Staphylococcus, Fuso-bacterium, and Bacteroides species. ${ }^{2}$ Predisposing factors include dental caries, recent dental treatment, systemic conditions such as diabetes mellitus, malnutrition, alcoholism, compromised immune system such as AIDS and organ transplantation. ${ }^{4}$ However, patients who are immunocompromised are commonly infected with an atypical organism, such as Pseudomonas, Escherichia coli, Candida, or Clostridium. ${ }^{12}$ The symptoms of Ludwig's angina vary depending on the patient and the degree of infection. Many general symptoms, such as pyrexia, weakness, and fatigue, develop as the result of the immune response associated with bacterial infection. The inflammatory response leads to edema of the neck and tissues of the submandibular, submax-illary, and sublingual spaces. Significant edema may cause trismus and an inability to swallow saliva. Pain, especially with tongue movement, is common with Ludwig's Angina. Symptoms marking progressive disease with significant obstruction of the airway include respiratory distress with dyspnea, tachypnea, or stridor. Confusion or other mental changes may occur because of prolonged hypoxia. Otalgia, dysphagia, dysphonia, and dysarthria are also observed. Occasionally, sepsis may even occur. If there is no immediate treatment, the submandibular infection may also rapidly spread to the mediastinal or pharyngomaxillary spaces or to the bone, resulting in osteomyelitis. An examination of the head and neck will demonstrate submandibular swelling characterized as calloused and tense. The neck under the chin and the floor of the mouth will be edematous and erythematous. The tongue will be enlarged because of swelling of the soft tissue underneath. Clinical signs associated with more progressive disease and airway obstruction include audible stridor, dysphonia, severe dehydration, and enlargement of cervical lymph nodes. The diagnosis of Ludwig's angina is made based on clinical presentation. The head, neck and tongue may appear red and swollen. The tongue swelling will progressively increase to occlude the airway. Computed tomography or magnetic resonance imaging scans are helpful in defining the extent and location of infection. ${ }^{13}$ In 1939, Grodinsky ${ }^{10,12,13}$ developed criteria for the diagnosis of Ludwig's angina, including: cellulitis involving the submandibular spaces bilaterally, with associated gangrene and serosanguineous, putrid infiltration of connective tissue, fascia, and muscles but not glandular tissues; and is spread by contiguity and not by lymphatics with minimal frank pus. 
Ludwig's Angina is considered as a dental emergency. ${ }^{1,10}$ Maintenance and protection of the airway are the most important component of the comprehensive management of Ludwig's angina. Ludwig's angina is potentially life threatening and require aggressive medical and surgical management. Early recognition is usually essential for the overall success in the management of these patients. The first line of management is surgical drainage, removal of the cause of the infection and drainage of accumulated pus and necrotic tissue. Microbial culture and sensitivity will indicate the appropriate antibiotics.

\section{Conclusion}

Early detection of Ludwig's angina followed by prompt diagnosis and commencement of appropriate antibiotics, as well as possible surgical intervention in the course of management remain a valid option to reducing severe morbidity. However, socioeconomic status and unrest due to insurgency have hampered early presentation and management.

\section{Acknowledgment}

Dr Thomas Owobu for conceptualization, design, acquisition of data and drafting and critical review of the manuscript, Dr. Edugie Ekuase: critical revision and final approval of the version of the manuscript submitted, Dr Oba Onisoman Azah: design and acquisition of data, Dr Sulaiman Shehu Adamu: design and acquisition of data and Prof. Babatunde O. Bamgbose: conceptualization, critical revision and final approval of version of manuscript submitted.

\section{Conflict of Interest}

The authors declared no conflicts of interest in this study.

\section{References}

1. Saifeldeen K, Evans R. Ludwig's angina. Emerg Med J 2004;21: 242-243.

2. Mccaskecyh. Ludwig's angina. Archives of ofolaryngology 1942;36: 467-472.

3. Nguyen VD, Potter JL, Hersh-Schick MR. Ludwig angina: an uncommon and potentially lethal neck infection. Am J Neuroradiol 1992;13: 215-219.

4. Moreland LW, Corey J, McKenzie R. Ludwig's angina. report of a case and review of the literature. Arch Intern Med 1988;148: 461-466.

5. Spitalnic SJ, Sucov A. Ludwig's angina: case report and review. J Emerg Med 1995;13: 499-503.

6. Fischmann GE, Graham BS. Ludwig's angina resulting from the infection of an oral malignancy. J Oral Maxillofac Surg 1985;43: 795-796.

7. Grod Nskmyd. Ludwig's angina: an anatomical and clinical study with review of the literature. Surg 1939;5: 678-696.

8. Owens BM, Schuman NJ. Ludwig's angina. Gen Dent 1994;42: 84-87.

9. Osunde O, Bassey G, Ver-Or N. Management of ludwig's angina in pregnancy: a review of 10 cases. Ann Med Health Sci Res 2014;4: 361-364.

10. Huang TT, Liu TC, Chen PR, et al. Deep neck infection: analysis of 185 cases. Head Neck 2004;26: 854-860.

11. Owens BM, Schuman NJ. Ludwig's angina: historical perspective. J Tenn Dent Assoc 1993;73: 19-21.

12. LeJeune HB, Amedee RG. A review of odontogenic infections. J La State Med Soc 1994;146: 239-241.

13. Williamsac, Guralnickkwc. The diagnosis and treatment of Ludwig's angina: report of 20 cases. N Engl J Med 1943;228: 43-50.

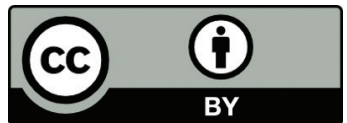

This work is licensed under a Creative Commons Attribution 